\title{
The Effect of Different Fibre Lengths on the Mechanical Properties of Biocomposites
}

\author{
HENDRA SUHERMAN ${ }^{*}$, KAMDINI AKSA ${ }^{1}$, YOVIAL MAHYOEDIN ${ }^{1}$, EDI SEPTE ${ }^{1}$, \\ IRMAYANI IRMAYANI ${ }^{2}$ \\ ${ }^{1}$ Department of Mechanical Engineering, Universitas Bung Hatta, 25143 Padang, West Sumatera-Indonesia \\ ${ }^{2}$ Department of Industrial Engineering, Universitas Ekasakti, 25133 Padang, West Sumatera-Indonesia
}

\begin{abstract}
Kenaf is a nonwoody fibrous plant, and its fibre can be potentially used as a reinforcement in the matrix to produce biocomposite materials. The properties of biocomposite materials are highly dependent on the reinforcing material and the matrix used as a binder. This study used kenaf fibre as a reinforcing material with different compositions $(10,20$, and $30 \mathrm{wt} . \%)$ and different fibre lengths $(1 \mathrm{~cm}$ and $3 \mathrm{~cm}$ ) in the matrix using the casting process. Low viscosity epoxy resin (635 thin epoxy resin) with a viscosity of 6 poise was used as the matrix. The results showed that the highest flexural strength, impact strength and shore hardness were obtained at a $30 \mathrm{wt} \%$ kenaf fibre composition with a 1-cm kenaf fibre length, namely, $85 \mathrm{MPa}, 338 \mathrm{KJ} / \mathrm{m}^{2}$ and $98 \mathrm{SHD}$, respectively. The length of the fibre in the matrix affects the mechanical properties of the resulting biocomposite. This condition is caused by kenaf fibres with a length of $1 \mathrm{~cm}$ being more dispersed in the matrix than fibres with a length of $3 \mathrm{~cm}$.
\end{abstract}

Keywords: Kenaf fibre, biocomposites, mechanical properties

\section{Introduction}

Kenaf belongs to the Malvaceae family and is a nonwoody fibrous plant. Kenaf fibres have the potential to be used as fillers or reinforcements in polymer matrices. The height of kenaf can exceed 3 $\mathrm{m}$, with a diameter of 3 to $5 \mathrm{~cm}$. If grown in good aeration and sufficient soil acidity, kenaf will have good fibre quality [1]. Some of the common fabrication processes that can be used to produce biocomposite materials are injection moulding, extrusion, casting, and compression moulding [2]. Barkoula et al. [3] reported that biocomposites produced using injection moulding produced lower impact strength values than those produced using compression moulding. Natural fibres and polypropylene (PP) as a matrix are a suitable combination that can be used to produce natural synthetic polymer composites [4]. Zampaloni et al. [5] used kenaf fibres as a reinforcing material and polypropylene (PP) as a binder (matrix). They arranged 130-mm-long kenaf fibres between two layers of PP sheets. They found that the distribution of kenaf fibres in the PP matrix was poor in the resulting biocomposite material. To obtain the distribution quality of kenaf fibre in the PP matrix, the kenaf fibre was chopped into a length of $20 \mathrm{~mm}$ and then mixed with the PP matrix using a mechanical stirrer. They found that the resulting biocomposite material formed a circular pattern in the PP matrix, so it was difficult to distribute the kenaf fibres evenly in the matrix. Lee et al. [6] conducted a study to investigate the effect of kenaf fibre orientation and lamination properties. They found that the mechanical properties increased with increasing fibre content with the orientation of the kenaf fibres parallel to the direction of the load. The highest tensile strength was obtained in the horizontal orientation at a $50 \%$ kenaf fibre content. They also reported that long fibres were easier to assemble and process than short fibres. This is because long fibres are easier to orient in the biocomposite manufacturing process [7]. Hao et al. [8] used kenaf fibre as the reinforcement and $\mathrm{PP}$ as the matrix to produce biocomposite materials. The ratio of kenaf fibre to the matrix used was 50/50 in injection moulding. The results obtained indicate that the mobility of liquid PP will increase at higher temperatures. This condition affects the bond formation of fibres in the matrix. The results obtained also indicate that the sample thickness of $6 \mathrm{~mm}$ is too thick. This is because a curing time of $1 \mathrm{~min}$ is not sufficient to transfer heat from the surface to the entire

\footnotetext{
*email:hendras@bunghatta.ac.id
} 
sample volume. Zamri et al. [9] conducted research on the effect of different fibre compositions and sizes using kenaf fibre as the reinforcement and polyester resin as the matrix. They found that the highest fibre loading concentration (70 vol\%) resulted in the highest flexural and compressive strength properties in the resulting biocomposite material, namely, 280 MPa and $75.73 \mathrm{MPa}$, respectively. Suriani et al. [10] conducted a study using kenaf fibres and epoxy to produce hybrid polymer composite materials. They reported that the tensile strength of hybrid kenaf fibre/PET yarn increased with increasing fibre volume content. In addition, the combination of kenaf fibre and PET yarn succeeded in increasing the tensile strength value of the resulting biocomposite material. This research was conducted to investigate the effect of adding kenaf fibres with different fibre lengths $(1 \mathrm{~cm}$ and $3 \mathrm{~cm})$ as a reinforcement and epoxy resin as a matrix on the flexural strength, impact strength and hardness of the biocomposite material obtained.

\section{Materials and method}

\subsection{Materials}

The kenaf fibre used in this study has an average diameter of $30 \mathrm{~mm}$, obtained from The National Kenaf and Tobacco Board - Malaysia. As the matrix, an epoxy resin with a low viscosity value (6 poise) was used, namely, 635 thin epoxy resin obtained from US Composites. A 4:1 ratio between epoxy resin and hardener was used as recommended by the manufacturer.

\subsection{Biocomposite manufacturing process}

The manufacturing process used to produce the biocomposite materials based on a predetermined composition is as follows. (1) The epoxy resin and hardener (4:1 ratio) were stirred using a mechanical stirrer (RW-IKA) for $10 \mathrm{~min}$ at $200 \mathrm{rpm}$. (2) Kenaf fibre based on a predetermined composition was stirred in using the same parameters. (3) The resulting mixture was poured into moulds and placed in an oven (TE0-11, Indonesia) at a temperature of $150^{\circ} \mathrm{C}$ for $30 \mathrm{~min}$. The weight percentages of kenaf fibre and epoxy resin and the length of kenaf fibre used are shown in Table 1.

Table 1. Percentages of kenaf fibre and epoxy resin and the fibre length in the biocomposites

\begin{tabular}{|c|c|c|}
\hline Kenaf fibre (wt.\%) & Epoxy (wt.\%) & Fibre length $(\mathrm{cm})$ \\
\hline 30 & 70 & 1 and 3 \\
\hline 20 & 80 & 1 and 3 \\
\hline 10 & 90 & 1 and 3 \\
\hline
\end{tabular}

\subsection{Characterization}

The resulting biocomposite material was characterized using (1) a flexural strength test (ASTM D 790 standard), (2) an impact test (ASTM E 23 standard), and (3) scanning electron microscopy (Hitachi $\mathrm{S}-3400 \mathrm{~N})$ to observe the dispersion of kenaf fibres in the epoxy matrix.

\section{Results and discussions}

\subsection{Effect of kenaf fibre on the flexural strength}

The flexural strength of biocomposite materials with variations in the composition of kenaf fibres $(10,20$, and $30 \mathrm{wt} . \%)$ and different lengths of kenaf fibres $(1 \mathrm{~cm}$ and $3 \mathrm{~cm})$ is shown in Figure 1 . The addition of kenaf fibre at 10 and $20 \mathrm{wt} . \%$ showed an increase in flexural strength for the two fibres with different lengths ( 1 and $3 \mathrm{~cm})$. Kenaf fibre with a length of $1 \mathrm{~cm}$ has a higher flexural strength value (75 $\mathrm{MPa})$ compared to kenaf fibre with a length of $3 \mathrm{~cm}(60 \mathrm{MPa})$. However, kenaf fibres with compositions of 20 and $30 \mathrm{wt} . \%$ showed different effects on the two lengths of kenaf fibres used. Different conditions were obtained for kenaf fibres with a length of $1 \mathrm{~cm}$ from 20 to $30 \mathrm{wt} . \%$, indicating that the flexural strength value of the biocomposite obtained continued to increase up to $85 \mathrm{MPa}$. 


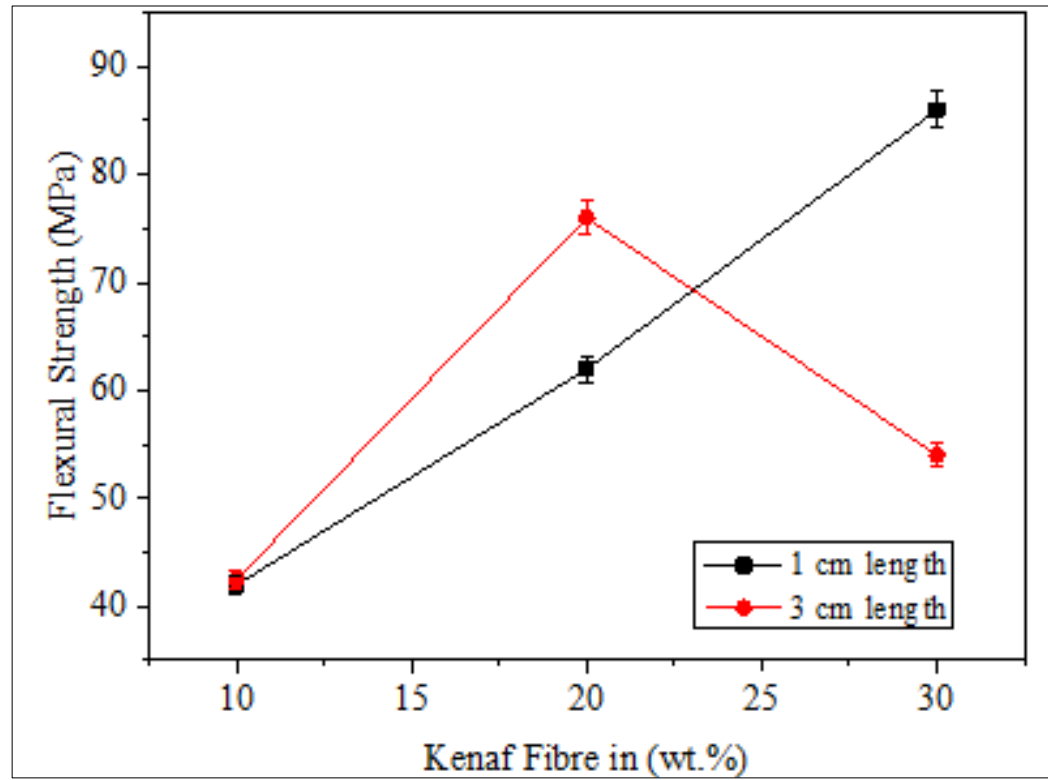

Figure 1. Effect of kenaf fibre on the flexural strength of biocomposite materials

Significant differences were obtained in biocomposite materials with the same composition of kenaf fibre (30 wt.\%) and different lengths of kenaf fibre, namely, $85 \mathrm{MPa}$ for kenaf fibre length of $1 \mathrm{~cm}$ and $53 \mathrm{MPa}$ for kenaf fibre length of $3 \mathrm{~cm}$. This significant difference is caused by the kenaf fibre with a length of $1 \mathrm{~cm}$ being able to fill almost all of the epoxy resin well, so that the number of voids formed in the epoxy resin is also less than that of the kenaf fibre, which is $3 \mathrm{~cm}$ long at the same composition of $30 \mathrm{wt} \%$. This condition resulted in the flexural strength value of the biocomposite material being significantly different even at the same composition [11-13].

\subsection{Effect of kenaf fibre on the impact strength}

Impact strength values with variations in the length of kenaf fibre $(1 \mathrm{~cm}$ and $3 \mathrm{~cm})$ and kenaf fibre filler loadings of 10, 20 and $30 \mathrm{wt} . \%$ are shown in Figure 2.

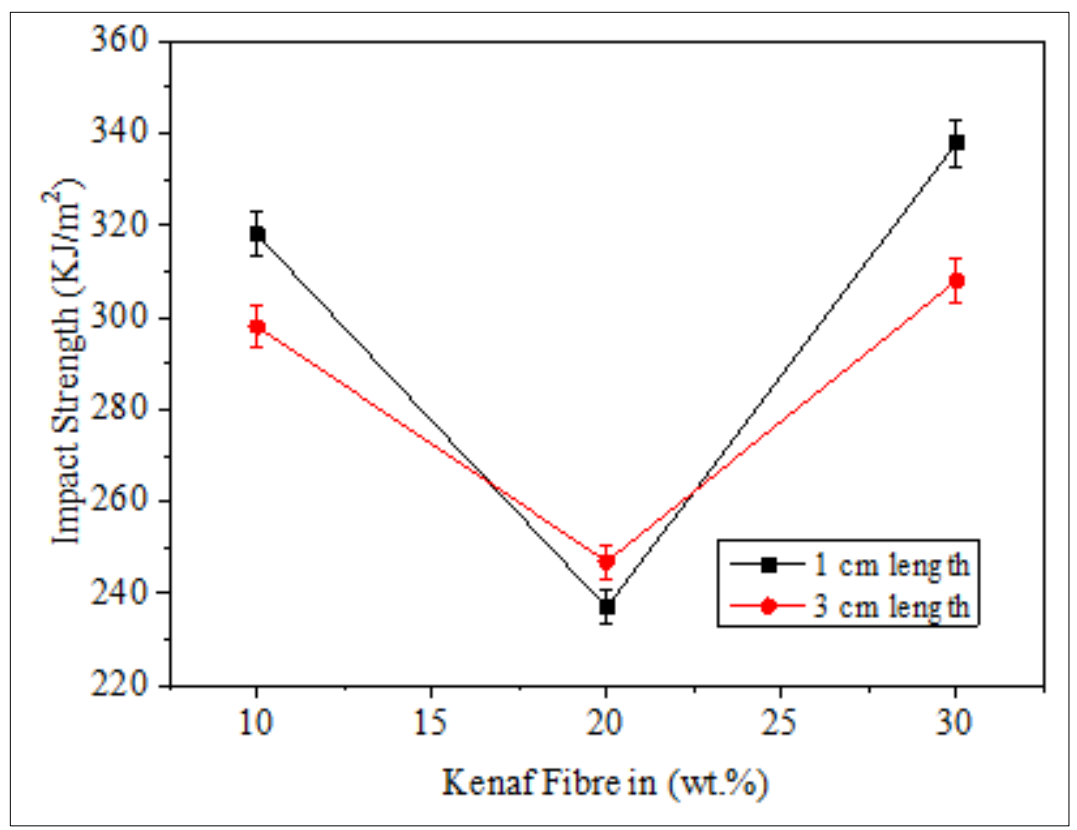

Figure 2. Effect of kenaf fibre on the impact strength of biocomposite materials 
In general, Figure 2 shows the same pattern of the resulting biocomposite material for the two different lengths of kenaf fibre $(1 \mathrm{~cm}$ and $3 \mathrm{~cm})$ in terms of impact strength. The addition of 10 and 20 wt.\% kenaf fibre for the two different lengths of kenaf fibre $(1 \mathrm{~cm}$ and $3 \mathrm{~cm})$ showed a drastic decrease in the impact strength value.

However, the addition of different lengths of kenaf fibre $(1 \mathrm{~cm}$ and $3 \mathrm{~cm})$ showed an increase in the impact strength value of biocomposites from 20 to $30 \mathrm{wt} . \%$, where kenaf fibre with a length of $1 \mathrm{~cm}$ had a higher impact strength value at $30 \mathrm{wt}$.\% fibre addition, i.e., $338 \mathrm{KJ} / \mathrm{m}^{2}$. This is due to the perfect bond between the kenaf fibre as a reinforcement and the epoxy resin as a binder [8,9]. Comparing kenaf fibres with different lengths $(1 \mathrm{~cm}$ and $3 \mathrm{~cm})$, kenaf fibres $1 \mathrm{~cm}$ long resulted in higher impact strength values at $30 \mathrm{wt} \%$ composition. This is because kenaf fibres with a length of $1 \mathrm{~cm}$ can fill the entire area of the epoxy resin matrix [11-14].

\subsection{Effect of kenaf fibre on the shore hardness}

The effect of the addition of kenaf fibre $(10,20$, and $30 \mathrm{wt} . \%)$ with variations in the kenaf fibre length $(1 \mathrm{~cm}$ and $3 \mathrm{~cm})$ on the shore hardness of the biocomposite material is shown in Figure 3. At the same load of $10 \mathrm{wt} . \%$ kenaf fibre in the epoxy resin, there were significant differences in the shore hardness values, namely, 97.9 SHD (length of $1 \mathrm{~cm}$ ) compared to 90.8 SHD (length of $3 \mathrm{~cm}$ ).

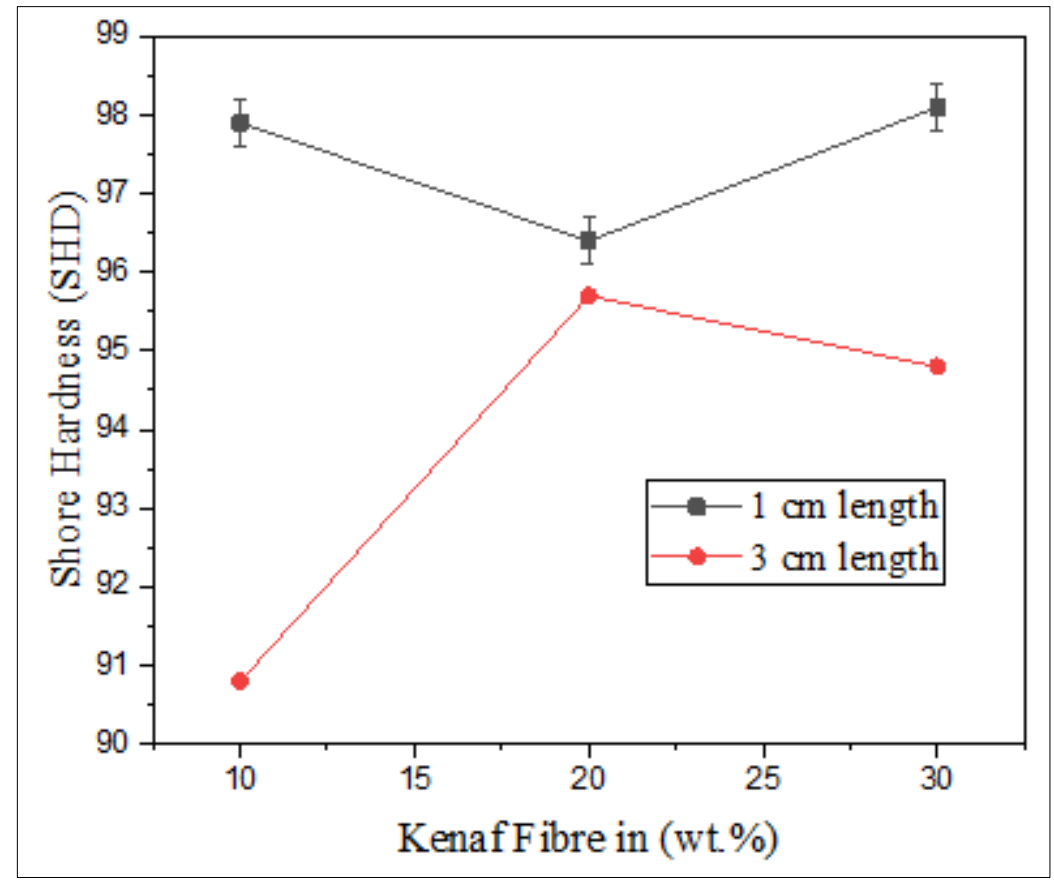

Figure 3. Effect of kenaf fibre on the shore hardness of biocomposite materials

This is because kenaf fibres with a length of $1 \mathrm{~cm}$ are better dispersed than kenaf fibres with a length of $3 \mathrm{~cm}$ in the polymer matrix so that the shore hardness value obtained is much higher [9]. At a load of $30 \mathrm{wt} . \%$ kenaf fibre with a length of $1 \mathrm{~cm}$, a higher shore hardness value was observed compared to that obtained from kenaf fibre with a length of $3 \mathrm{~cm}$, namely, 98 SHD vs. 94.8 SHD. Suriani et al. [10] also found that shorter fibres in the polymer matrix resulted in better mechanical property values, which was due to the shorter fibres being able to fill the entire polymer matrix so that there were fewer voids in the polymer matrix. 


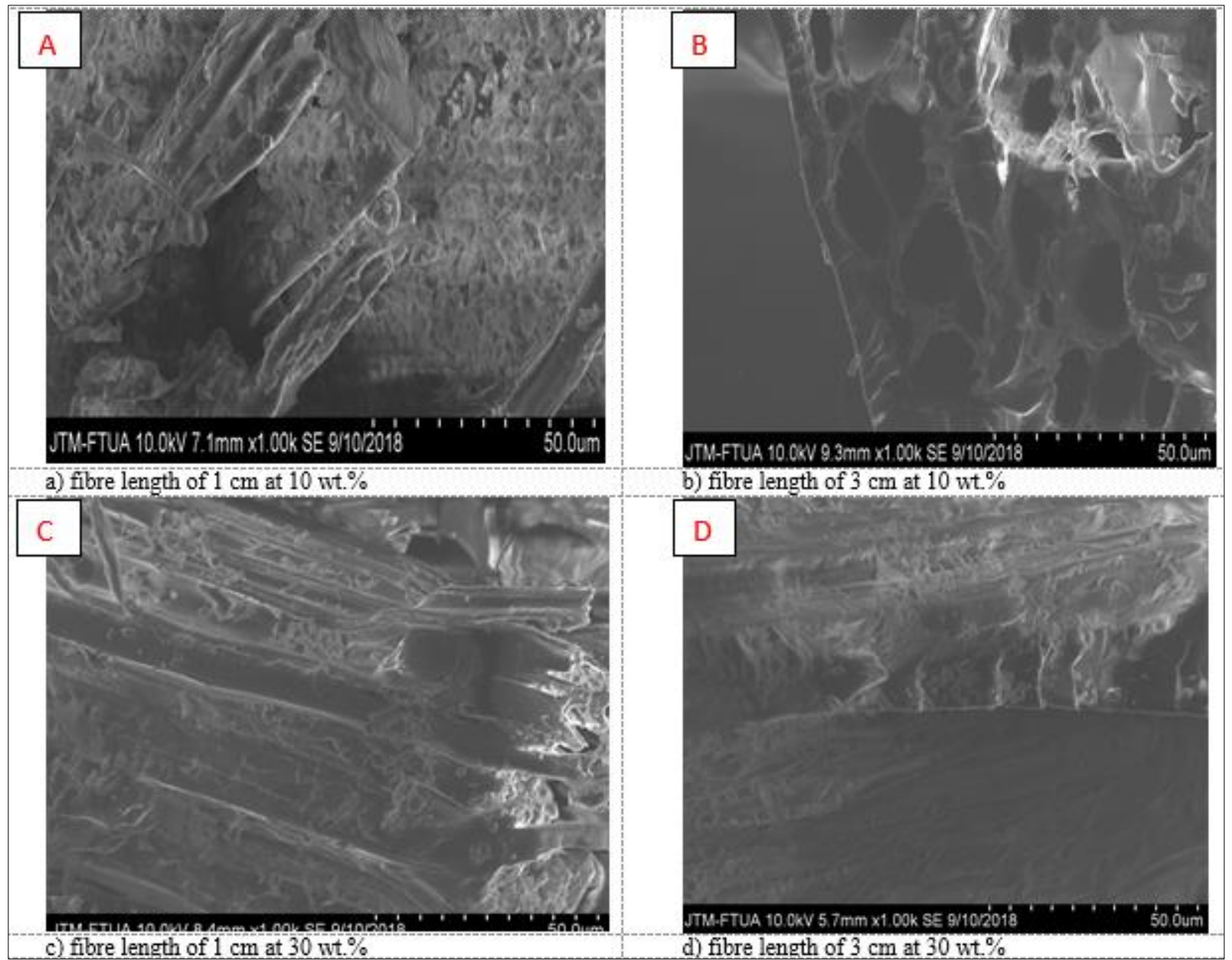

Figure 4. Scanning electron microscopy (SEM) images of the fracture surface of kenaf fibre/epoxy biocomposites

Figure 4 shows SEM images of the fracture surface of the resulting biocomposite material. Figures 4a and $4 \mathrm{c}$ show that 1-cm-long kenaf fibres at $10 \mathrm{wt} . \%$ and $30 \mathrm{wt} . \%$ compositions were well dispersed in the matrix (epoxy resin) compared to $3 \mathrm{~cm}$ long fibres at the same compositions of $10 \mathrm{wt} \%$ and 30 wt.\%. This condition resulted in better flexural strength, impact strength and shore harness [9]. On the other hand, Figures 4 (b) and 4 (d) show that 3-cm-long kenaf fibres at the same composition, namely, $10 \mathrm{wt} . \%$ and $30 \mathrm{wt} . \%$, tend to agglomerate and have some cavities. This condition has an impact on the low tensile strength, impact strength and shore hardness of the resulting biocomposite material [10].

\section{Conclusions}

The investigation of biocomposite materials using kenaf fibre as the reinforcement and low-viscosity epoxy resin as the matrix using the casting process was completed. The conclusions are as follows:

-The addition of kenaf fibre as a reinforcement succeeded in increasing the flexural strength, impact strength, and shore hardness of the resulting biocomposite material;

-Kenaf fibres with a length of $1 \mathrm{~cm}$ produce a biocomposite material that has a higher flexural strength, impact strength and shore hardness than kenaf fibres with a length of $3 \mathrm{~cm}$;

-The length of the kenaf fibre used as reinforcement greatly affects the resulting biocomposite material. Longer kenaf fibres tend to agglomerate and cannot be well dispersed throughout the matrix, while shorter kenaf fibres are more easily dispersed and can fill the entire matrix better. 
Acknowledgements: The authors acknowledge the Director General of Higher Education ministry of Education and Culture Republic Indonesia, DIPA Number: SP-DIPA-023.17.1.690439/2021. SPPK Number: 170/E4.1/AK.04.PT/2021 and based on the basic contract and guidance/multi-year capacity for the 2021 fiscal year, Number: 011/LL10/PG-PDTJ/2021, 069/LPPM-PDJ/Hatta/VII-2021 dated 14 July 2021, 15 July 2021.

\section{References}

1.AKIL H. M., OMAR M. F., MAZUKI A. A., SAFIEE M., ISHAK S., BAKAR A, Kenaf fiber reinforced composites: A review, Mater. Des. 32, 2011, 4107.

2.SHUBHRA Q.T., ALAM A., QUAIYYUM M., Mechanical properties of polypropylene composites: A review, J. Thermo. Compos. 26, 2011, 362.

3.BARKOULA, N. M., GARKHAIL, S.K., PEIJS, T, Biodegradable composites based on flax/polyhydroxybutyrate and its copolymer with hydroxyvalerate, Ind. Crop. Prod. 31, 2010, 34.

4.LEE, S., SHI, S., GROOM, L., XUE, Y, Properties of unidirectional kenaf fiber-polyolefin laminates, Polym. Compos.31, 2010, 15.

5.ZAMPALONI, M., POURBOGHRAT, F., YANKOVICH, S.A., RODGERS, B.N., MOORE, J., DRZAL, L.T., MISRA, M, Kenaf natural fiber reinforced polypropylene composites: A discussion on manufacturing problems and solutions, Compos. Part A: Appl. Sci. Manu. 38, 2007, 1569.

6.MAHJOUB, R., YATIM, J.M., SAM, A.R.M., RAFTARI, M, Characteristics of continuous unidirectional kenaf fiber reinforced epoxy composites, Mater. Des. 64, 2014, 640.

7.FIORE, V., DI BELLA, G., VALENZA, A, A review on basalt fibre and its composites, Compos. Part B: Eng. 68, 2015, 74.

8.HAO, A., ZHAO, H., JIANG, W., YUAN, L., CHEN, J.Y, Mechanical properties of kenaf/polypropylene nonwoven composites, J. Polym. Environ. 20, $2012,959$.

9. ZAMRI, M. H., AKIL, H. MD., ISHAK, Z.A. M., BAKAR, A. A, Effect of different fiber loadings and sizes on pultruded kenaf fiber reinforced unsaturated polyester composites, Polym. Compos. 36, $2015,1224$.

10.SURIANI, M. J., ZAINUDIN, H.S., ILYAS, R. A., MICHAL, P.U., SAPUAN, S. M., RUZAIDI, C. M., MUSTAPHA, R., Kenaf Fiber/Pet Yarn Reinforced Epoxy Hybrid Polymer Composites: Morphological, Tensile, and Flammability Properties, Polymers, 13, 2021, 1532.

11.SUHERMAN H., AZWAR E, DUSKIARDI, YOVIAL, SEPTE E, Properties of Kenaf Fiber/Epoxy Biocomposites: Flexural Strength and Impact Strength, IOP Conf. Series: Mater. Scie. Eng. 625, 2019, 1 .

12.LEE, B.H., KIM, H.S., LEE, S., KIM, H.J., DORGAN, J.R, Bio-composites of kenaf fibers in polylactide: Role of improved interfacial adhesion in the carding process, Compos. Sci. Technol. 69, 2009, 2573.

13.PICKERING, K.L., ARUAN EFENDY, M.G., LE, T.M, A review of recent developments in natural fibre composites and their mechanical performance, Compos. Part A. Appl. Sci. Manu. 83, 2016, 98.

14.SANJAY, M.R., MADHU P., JAWAID M., SENTHAMARAIKANNAN P., SENTHIL S., PRADEEP S, Characterization and properties of natural fiber polymer composites: A comprehensive review, J. Cleaner Production, 172, 2018, 566.

Manuscirpt received: 31.10 .2021 